\title{
Outcome of management of gastroschisis: comparison of improvised surgical silo and extended right hemicolectomy
}

\author{
Philemon E. Okoro ${ }^{1,2^{*}}$ (i) and Charles Ngaikedi ${ }^{2}$
}

\begin{abstract}
Background: Gastroschisis is onea of the major abdominal wall defects encountered commonly in pediatric surgery. Whereas complete reduction and abdominal closure is achieved easily sometimes, a daunting situation arises when the eviscerated bowel loops and other viscera cannot be returned immediately into the abdominal cavity. This situation is a major contributor to the outcome of the treatment of gastroschisis in our region. In our efforts to improve our outcome, we have adopted the technique of extended right hemicolectomy for cases where complete reduction and primary abdominal wall closure is otherwise not possible. This study compared the management outcome of gastroschisis using our improvised silo, and performing an extended right hemicolectomy.

Results: Thirty-nine cases were analyzed. Simple closure could not be achieved in 28 cases. In the absence of standard silos, improvised ones were constructed from the amniotic membrane (3 cases), urine bag (4 cases), and latex gloves (9 cases) giving a total of 16 cases managed with silos. Extended right hemicolectomy was performed in 12 cases.
\end{abstract}

Conclusions: Given the peculiarities of circumstances in our region regarding human and material resources in the care of gastroschisis patients, an extended right hemicolectomy, to make it possible to close the abdomen primarily in gastroschisis is a more viable option than the use of improvised silo.

Trial registration: This trial was approved by the Ethical Committee of the University of Port Harcourt Teaching Hospital, Nigeria. Reference Number: UPTH/ADM/90/S.IINOL XI/835. Registered 3 May 2013.

Keywords: Gastroschisis, Extended right hemicolectomy, Improvised silo, Closure, Morbidity, Mortality

\section{Background}

Gastroschisis is one of the major abdominal wall defects encountered commonly in pediatric surgery. It represents one of the most challenging defects requiring emergency surgical correction [1]. Treatment of this condition in sub-Saharan Africa has been met with high morbidity and mortality rates in the range of $30-100 \%$ [2-4]. This is in clear contrast with the scenario in the high-income countries where mortality rates are as low as $4 \%$ in many institutions [5-7]. The amount of viscera outside the abdomen varies from one case to the other.

\footnotetext{
* Correspondence: philemon.okoro@uniport.edu.ng

${ }^{1}$ Paediatric Surgery Unit, Department of Surgery, University of Port Harcourt

Teaching Hospital, Port Harcourt, Nigeria

${ }^{2}$ Department of Surgery, Federal Medical Centre, Imo State, Owerri, Nigeria
}

Also, associated anomalies like intestinal malrotation, bowel atresia, and undescended testis are common [8]. Whereas complete reduction and abdominal closure are achieved sometimes, a daunting situation arises when the eviscerated bowel loops and other viscera cannot be returned immediately into the abdominal cavity. A need to house the viscera temporarily outside becomes imperative. This comes with the requirements to control infection, support nutrition and support, if not take over, respiration. This inability to completely reduce the viscera in gastroschisis is related to the edema and matting together of the loops of the bowel due to prolonged exposure to amniotic fluid. Post-delivery, the edema is worsened by desiccation, minor trauma due to handling and infection. This is the basis some authors recommend 
early or premature delivery of these babies to reduce the duration of contact with amniotic fluid [9-12]. However, whether early delivery reduces mortality in gastroschisis is yet to be scientifically tested. In our circumstance, many of these patients come in already exposed to the assaults of contamination, hypothermia, hypoglycemia, and sometimes desiccation of some parts of the viscera, and neonatal intensive care facilities and resources are limited [13]. The use of silo in these circumstances is therefore often met with discouraging results. We aimed in this study, to compare the management outcome using surgical silo and performing an extended right hemicolectomy in the treatment of gastroschisis.

\section{Methods}

A proforma was designed to retrospectively obtain data from the medical records of consecutive cases of gastroschisis managed in our units in our two health institutions from June 2006 to May 2013. Ethical approval was obtained from the institutional review boards of the two institutions where this study was carried out. Written consent was also obtained from the parents of the patients who were recruited prospectively. We added the use of extended right hemicolectomy (ERH) from 2013 and prospectively obtained data from May 2013 to April 2018. We defined ERH as the surgical removal of the terminal ileum about $3 \mathrm{~cm}$ proximal to the ileocaecal junction, the caecum, ascending colon and more than half of the transverse colon, followed by an ileotransverse anastomosis. In all cases, efforts were made to reduce the bowel and close the abdomen primarily. Before May 2013, all cases that could not be closed had a surgical silo (Silo group) but from 2013 such cases were selected for extended right hemicolectomy (ERH group). At surgery, the bowel was carefully inspected for the presence of volvulus, atresia, or gangrene. The bowel was cleaned using warm normal saline. Separation of the matted bowel loops was limited to only the extent required to enable safe resection and anastomosis. This was aimed at reducing blood loss, though the majority received blood transfusion intraoperatively. Any gas and or meconeum in the matted bowel was milked into the right hemicolon before its excision. Any volvulus was untwisted, and any gangrenous segment incorporated into the resection where possible. Data collected from the records of the patients seen before 2013 included gender, age at presentation and intervention, viscera seen on the outside, method of repair, any nutritional support, and outcome. The same data was obtained prospectively from 2013. Data obtained were subjected to statistical analysis on SPSS version 20.0. The level of statistical significance was set at $p<0.05$.

\section{Results}

A total of 43 infants with gastroschisis were seen in the study period. Four infants were excluded due to incomplete records and discharge against medical advice. Thirty-nine patients were included in the study. There were 22 (56.4\%) females and 17 (43.6\%) males. Prenatal diagnosis was made only in $2(5.1 \%)$ patients. The mean age at presentation was $10.8 \mathrm{~h}( \pm 3.2)$ for the Silo group, and $8.7 \mathrm{~h}( \pm 2.1)$ for the ERH group; $p<0.1$. None of the patients received standard parenteral nutritional support. All patients in whom oral feeds could not be established within 5 days received an amino acid infusion. All patients went through similar protocols of evaluation and resuscitation and general treatment. Eight (20.5\%) patients were seen within $6 \mathrm{~h}$ of delivery (Table 1) with less oedematous bowel (Fig. 1a) whereas the rest were seen later (Fig. 1b). The most common viscera exposed were the small and large bowels (Table 2). Of the 39 patients analyzed, 2 (5.1\%) died before any surgical intervention and 1 (2.6\%) was unfit for any surgery and he died within an hour of arrival. There was complete reduction and primary fascial closure of the defect in 8 (20.5\%)patients, and of these 2 died (25\% mortality). Skin closure could not be achieved in 28 (71.8\%) cases. In the absence of standard silos, improvised ones (surgical silo) were constructed from amniotic membrane (3 patients) (Fig. 2), urine bag (4 patients), and latex gloves (9 patients) giving a total of 16 patients managed with improvised surgical silos (Silo group). One patient out of the 16 patients in the silo group survived giving 6.3\% survival $(93.7 \%$ mortality). Mortality in this improvised silo group was related to severe sepsis, premature detachment of silo, lack of nutritional support and respiratory failure. Extended right hemicolectomy was performed in 12 (30.8\%) patients (ERH group). Eight out of the 12 patients in this group survived giving a $66.7 \%$ survival. The morbidity and mortality in this group were related to severe sepsis, anastomotic leakage, and intestinal obstruction. All surviving patients were followed up for a mean period of 2.5 years. One patient who had a simple reduction and primary closure developed intestinal obstruction 6 months after closure. A laparotomy revealed volvulus of the midgut, and patient recovered fully the following correction. One patient in the ERH group developed post-op adhesive bands obstruction which necessitated a second surgery. He also developed a small incisional hernia which is being considered for a repair. The outcome of the treatment options is shown in Table 3 . The difference in survival in the Silo group and the ERH group was statistically 
Table 1 Age of patients at presentation and at intervention

\begin{tabular}{llllll}
\hline Age $(\mathrm{h})$ & $0-6$ & $6-12$ & $12-18$ & $18-24$ & $24-48$ \\
\hline Patients at presentation $(n=39)$ & $8(20.5 \%)$ & $23(59.0 \%)$ & $5(12.8 \%)$ & $3(7.7 \%)$ & - \\
Patients at time of intervention $(n=36)$ & $4(11.1 \%)$ & $7(19.4 \%)$ & $13(36.1 \%)$ & $7(19.4 \%)$ & $5(12.8 \%)$
\end{tabular}

significant $(p<0.05)$. Out of 36 patients who were treated for gastroschisis, 17 survived giving an overall survival rate of $(41.7 \%)$.

\section{Discussion}

Gastroschisis ranks among the severe congenital anomalies that continue to pose a challenge to pediatric surgeons. The challenges which relate to morbidity and mortality include prematurity, low birth weight, compromised bowel, sepsis, and surgical complications [14, 15].

The majority of the patients in our study presented similar scenarios of low birth weight, viscera wrapped in an unclean wrapper, without proper warming of baby and moved over long distances to reach us. The picture is worse in the presence of atresia, bowel perforation, volvulus, or other anomalies [16]. In our series, there was only one case colonic atresia, and two cases of perforated and gangrenous bowel.

Despite advances in knowledge and technology, the outcome of treatment of gastroschisis is still less than expected for patients requiring surgical silo. Hence,
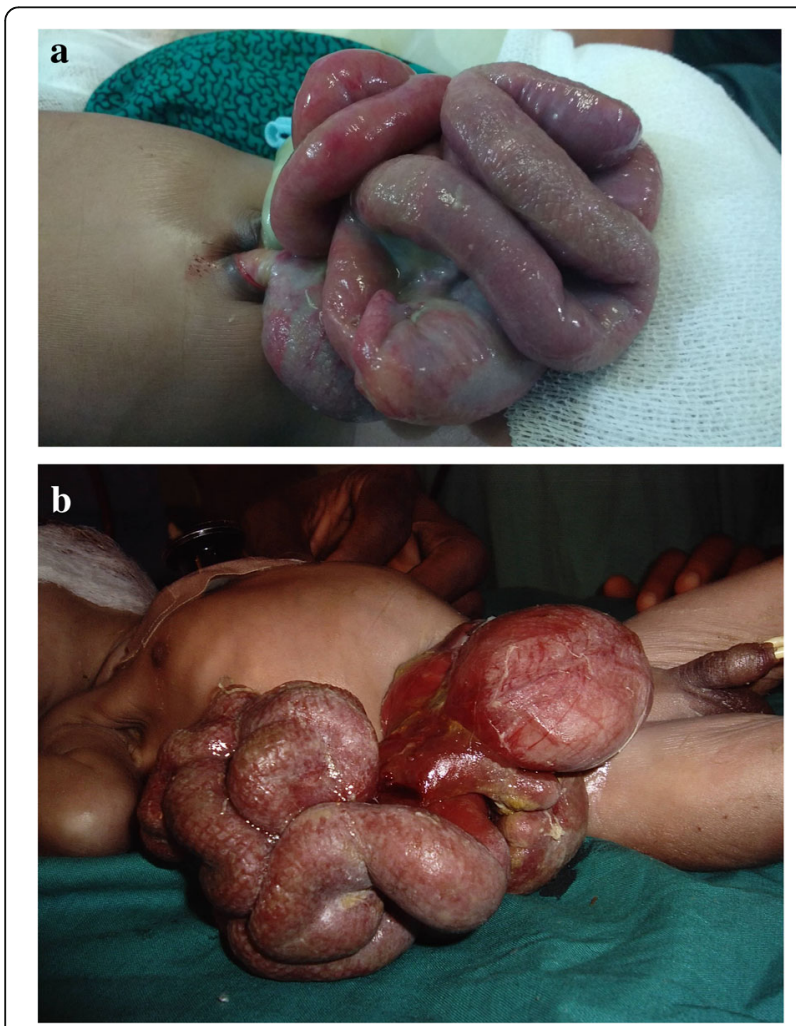

Fig. 1 a Gastroschisis seen early. b Gastroschisis seen delayed researchers have tried and continue to try different maneuvers and techniques to further improve on what has been achieved [17]. Presently, standard surgical modalities for the treatment of gastroschisis, include reduction and primary fascial or skin flap closure, or partial reduction and use of silastic silo to allow for delayed fascial closure [18]. Primary fascial closure is the preferred method provided the entire viscera can be returned to the abdominal cavity without the risk of abdominal compartment syndrome or compromise of respiration. These are the principles we also used for our patients. However, in our circumstance, patients requiring silo treatment could only be treated with improvised ones as this study shows.

Some have recommended preterm delivery of these babies to reduce the deleterious effect of the amniotic fluid on the viscera [19]. This idea enhances outcomes where the majority of cases are diagnosed prenatally with imaging. Such imaging can also help in predicting the outcome of treatment $[19,20]$. However, this method is not viable in our situation as prenatal diagnosis of gastroschisis is uncommon in our practice. Only three patients in this series were diagnosed prenatally. More so, the quality of neonatal intensive care available to us may not justify that mode of treatment [21].

The crux of this study was to address the peculiar management challenges in our region where the option of use of silo is attended with unacceptably high mortality. This study highlights the lateness of presentation and intervention with only $20.5 \%$ presenting within $6 \mathrm{~h}$ of birth and $11.1 \%$ being treated within that time frame. These challenges, in addition to lack of parenteral nutrition, functional neonatal intensive care units and pediatric ventilators have been reported by other researchers in our region [4, 22, 23]. We were constrained by the lack of standard silos to use amniotic membrane, latex gloves, drip bags, and urine bags at various times to improvise silos. We have also tried to adopt the innovative technique of sutureless gastroschisis closure

Table 2 Viscera exposed at presentation

\begin{tabular}{lll}
\hline Exposed viscera & Patients $(n=39)$ & Percentages \\
\hline Small bowel & 39 & 100 \\
Large bowel & 37 & 94.9 \\
Stomach & 18 & 46.2 \\
Urinary bladder & 9 & 23.1 \\
Liver and gall bladder & 7 & 17.9 \\
\hline
\end{tabular}




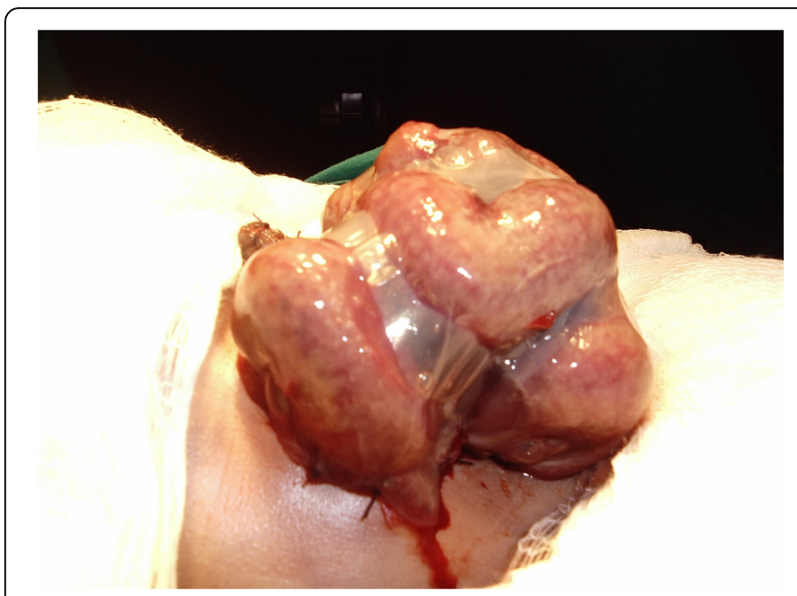

Fig. 2 Silo improvisation

[24]. None of these gave us any result as encouraging as we have seen with extended right hemicolectomy.

Though gastroschisis had not been a common indication for colonic resection in our region, this trend may change with the findings of this study [25]. We noted in the course of this study, the technical difficulty of performing anastomosis in the edematous matted loops of bowel in gastroschisis. This indeed accounted for some of the mortalities in the ERH group. Contrary to our initial concerns, aside from the initial frequent stooling, there was no evidence of short bowel syndrome, poor weight gain, or impaired growth during the period of follow up in the patients who were treated with ERH.

An improvement from a survival rate of $6.3 \%$ in patients managed with our improvised silo to $66.7 \%$ in patients managed with extended right hemicolectomy and immediate fascial closure is remarkable. Though this does not measure up with the results reported by authors in the high-income countries, we consider it a significant advancement in our management of gastroschisis [3, 7].

We recognize the limitations of this study because of the small volume of patients, and the fact that the

Table 3 Outcome of management of gastroschisis

\begin{tabular}{|c|c|c|c|c|c|}
\hline Treatment method & $\begin{array}{l}\text { Number } \\
\text { treated }\end{array}$ & $\begin{array}{l}\text { Number } \\
\text { survived }\end{array}$ & $\begin{array}{l}\text { Number } \\
\text { died }\end{array}$ & $\begin{array}{l}\text { Percentage } \\
\text { survival }\end{array}$ & $\begin{array}{l}\text { Overall } \\
\text { surviva }\end{array}$ \\
\hline $\begin{array}{l}\text { Immediate } \\
\text { reduction and } \\
\text { closure }\end{array}$ & 8 & 6 & 2 & 75 & $41.7 \%$ \\
\hline $\begin{array}{l}\text { Improvised silo and } \\
\text { delayed closure } \\
\text { (Silo group) }\end{array}$ & 16 & 1 & 15 & 6.3 & \\
\hline $\begin{array}{l}\text { Extended right } \\
\text { hemicolectomy and } \\
\text { immediate fascial } \\
\text { closure of defect } \\
\text { (ERH group) }\end{array}$ & 12 & 8 & 4 & 66.7 & \\
\hline
\end{tabular}

improvised silos are not standardized. A larger-scale multicenter study is required to properly test the option of extended right hemicolectomy and immediate fascial closure versus the use of surgical silo in the treatment of gastroschisis. However, our preliminary results in this study suggest that this technique has a potential to turn around the tide in the outcome of the treatment of gastroschisis in our region.

\section{Conclusions}

This study has demonstrated that gastroschisis still remains a major challenge in pediatric surgical practice in our region. Late presentation, delayed intervention, high infection rate, lack of parenteral nutritional support, and unavailability of standard silos remain our bane in the management of gastroschisis. Given these peculiarities of our circumstances regarding human and material resources in the care of these patients, and given the improved outcome with the option of extended right hemicolectomy, this second alternative is a more viable option than the use of improvised silo in our region.

\section{Abbreviations}

ERH: Extended right hemicolectomy; SPSS: Statistical Package for the Social Sciences

\section{Acknowledgements}

Not applicable

\section{Authors' contributions}

OPE conceived and conceptualized the idea of the study, did the literature review, data collection and collation, analysis of data, and manuscript writing. NC did the data collection and collation, data analysis, and critical review of the manuscript. Both authors read and approved the final manuscript.

\section{Funding}

This study was fully funded by the authors. There was no financial assistance or support from any individual or organization.

Availability of data and materials

All data generated or analyzed during this study are included in this published article [and its supplementary information files].

\section{Ethics approval and consent to participate}

Ethical approval was obtained from the ethics committee of the University of Port Harcourt Teaching Hospital with reference number UPTH/ADM/90/S.II/ VOL XI/835, and the Federal Medical Centre Owerri. Written informed consent was also obtained from the parents of patients who were recruited prospectively.

\section{Consent for publication \\ The consent for publication was verbally obtained from parents and guardians of the participants.}

Competing interests

The authors declare that they have no competing interests.

Received: 8 October 2019 Accepted: 26 November 2019 Published online: 08 January 2020

\section{References}

1. Rachael TO, Daniel AD, Megan LS, et al. Factors associated with gastroschisis outcomes. Obstet Gynecol. 2014;124:551-7. 
2. Ameh EA, Seyi-Olajide JO, Sholadoye T. Neonatal surgical care: a review of the burden, progress and challenges in sub- Saharan Africa. Paediatr Int Child Health. 2015;35:243-51.

3. Wright NJ, Zani A, Ade-Ajayi N. Epidemiology, management and outcome of gastroschisis in Sub-Saharan Africa: Results of an international survey. Afr J Paediatr Surg. 2015;2:1-6.

4. Osifo OD, Evbuomwan I, Efobi CA. Presentation and management of gastroschisis: Experience in 8 years in Benin-City, Nigeria. Sahel Med Journal. 2007:10:115-8

5. Ford K, Poenaru D, Moulot O, et al. Gastroschisis: Bellwether for neonata surgery capacity in low resource settings? J pedsurg. 2016;51:1262-126.

6. Bradnock TJ, Marven S, Owen A, et al. Gastroschisis: One year outcomes from national cohort study. BMJ. 2011;343:6749.

7. Kirby RS, Marshall J, Tanner JP, et al. Prevalence and correlates of gastroschisis in 15 states, 1995 to 2005. Obstet Gynecol. 2013;122:275-81.

8. Lee TC, Barshes NR, Nguyen L, et al. Gastroschisis and biliary atresia in a neonate: uncommon presentation or common precipitant. Eur J Pediatr Surg. 2005;15:434-6.

9. Burge DM, Ade-Ajayi N. Adverse outcome after prenatal diagnosis of gastroschisis: the role of fetal monitoring. J Pediatr Surg. 1997;32:441-4.

10. Baud D, Lausman A, Alfaraj MA. Expectant management compared with elective delivery at 37 weeks for gastroschisis. ObstetGynecol. 2013;121:990-8.

11. Meyer MR, Shaffer BL, Doss AE. Prospective risk of fetal death with gastroschisis. J Matern Fetal Neonatal Med. 2015;28:2126-9.

12. Carnaghan H, David B, Eveline LK, et al. Effect of gestational age at birth on neonatal outcomes in gastroschisis. J Pediatr Surg. 2016;51:734-8.

13. Manson J, Ameh EA, Canvassar N, et al. Gastroschisis: a multi-centre comparison of management and outcome. Afr j paediatr Surg. 2012;9:17-21.

14. Sanseverino MT, Gomes KW, Magalhães JA. Associated factors for perinatal mortality in gastroschisis. Rev Bras GinecolObstet. 2013;35:549-53.

15. Tarcă E, Ciongradi I, Aprodu SG. Birth weight, compromised bowel and sepsis are the main variables significantly influencing outcome in gastroschisis. Chirurgia (Bucur). 2015;110:151-6.

16. Bergholz $\mathrm{R}$, Boettcher $\mathrm{M}$, Reinshagen $\mathrm{K}$, et al. Complex gastroschisis is a different entity to simple gastroschisis affecting morbidity and mortality-a systematic review and meta-analysis. J PediatrSurg. 2014;49(10):1527-32.

17. Aldrink JH, Caniano DA, Nwomeh BC. Variability in gastroschisis management: a survey of North American pediatric surgery training programs. J Surg Res. 2012;176(1):159-63.

18. Patrick MC, Daniel JL, John JM, et al. Contemporary trends in the use of primary repair for gastroschisis in surgical infants. Am J Surg. 2015;209:901-6.

19. Rachael P, Zachary MF, Felipe M, et al. Gastroschisis: antenatal sonographic predictors of adverse neonatal outcome. J Pregnancy. 2014;1-13:239406 Published online 2014 Dec 22.

20. Robertson JA, Kimble RM, Stockton $\mathrm{K}$, et al. Antenatal ultrasound features in fetuses with gastroschisis and its prediction in neonatal outcome. Aust N Z J ObstetGynaecol. 2017;57:52-6.

21. Carnaghan H, Pereira S, James CP. Is early delivery beneficial in gastroschisis? J Pediatr Surg. 2014;49:928-33.

22. Uba AF, Chirdan LB. Omphalocoele and gastroschisis: management in a developing country. Nig J Surg Res. 2003;5:57-61.

23. Wesonga AS, Fitzgerald TN, Kabuye R, et al. Gastroschisis in Uganda: opportunities for improved survival. J Pediatr Surg. 2016;51:1772-7.

24. Riboh J, Abrajano CT, Garber K, et al. Outcomes of sutureless gastroschisis closure. J pediatrsurg. 2009;44(10):1947-51.

25. Ameh EA. Bowel resections in children. East Afr Med J. 2001;78(9):477-9.

\section{Publisher's Note}

Springer Nature remains neutral with regard to jurisdictional claims in published maps and institutional affiliations.

\section{Submit your manuscript to a SpringerOpen ${ }^{\circ}$ journal and benefit from:}

- Convenient online submission

- Rigorous peer review

- Open access: articles freely available online

High visibility within the field

- Retaining the copyright to your article

Submit your next manuscript at $\boldsymbol{\nabla}$ springeropen.com 